\title{
DNA Barcode, una alternativa para identificar especies del Complejo Midas Cichlidae en Nicaragua
}

\section{Lucía Páiz-Medina y Jorge A. Huete-Pérez}

Centro de Biología Molecular, Universidad Centroamericana, Rotonda Rubén Darío, 500 mts al oeste, Apto. Postal 69. Managua, Nicaragua. Tel: 278-3923 Ext. 1189. Correo electrónico: lupame_09@yahoo.com, huete@ns.uca.edu.ni

EL COMPLEJO MIDAS CICHLIDAE (especies del género Amphilophus) ha sido objeto de discusión entre diferentes grupos de científicos debido a que desde los primeros intentos de su clasificación taxonómica presentó problemas dada la similitud morfológica entre especies del Complejo. Inicialmente se pensó que era solamente una especie polimórfica pero, luego de realizar diferentes estudios, se sabe que son diferentes especies. DNA Barcode (Código de Barras genético) es una técnica moderna que se está implementando en el Centro de Biología Molecular, y que pretende identificar las diferentes especies del Complejo Midas Ciclhidae utilizando una secuencia relativamente corta del gen mitocondrial COI.

Palabras clave: DNA Barcode / Complejo Midas Cichlidae / Nicaragua

\section{Introducción}

Uno de los objetivos de las ciencias biológicas, especialmente de la sistemática, ha sido la clasificación de los seres vivos de acuerdo a sus características morfológicas y de comportamiento para facilitar y universalizar su estudio.

En Nicaragua existe un grupo de peces perteneciente a la familia Cichlidae, género Amphilophus, que desde los primeros intentos de clasificación ha sido objeto de discusión debido a que algunos son muy parecidos morfológicamente y no fue posible diferenciarlos y clasificarlos. Se pensaba que solamente existía una especie y que ésta presentaba diferentes formas (Mckaye y Stauffer, 2002).

En los últimos años se han reportado nuevas especies para este género y se piensa que podrían ser muchas más, y que probablemente hayan evolucionado a partir de un ancestro común Amphilophus citrinellus (reportado por Günther, 1864) que existía originalmente en lagunas cratéricas de Nicaragua (Xiloá y Apoyo). 
El complejo Midas Cichlidae, como se ha denominado a dichas especies, es de gran importancia para la ciencia debido a su significado evolutivo. Se plantean las siguientes preguntas: ¿cuántas especies son realmente? Y ¿cómo ha ocurrido el proceso de especiación? Grupos de investigadores de diferentes países se han interesado en el Complejo y han realizado diferentes estudios para responder esas interrogantes y descifrar el mecanismo evolutivo implicado.

El Centro de Biología Molecular de la Universidad Centroamericana, con el objetivo de promover la investigación nacional y de aportar al estudio de la familia Cichlidae, lleva a cabo una investigación en la que se implementa una técnica moderna denominada "DNA Barcode" (Código de barras genético) para conocer, por medio de análisis genéticos, las especies que habitan en los lagos de Nicaragua y lagunas de origen cratérico.

En este artículo exponemos las principales consideraciones taxonómicas actuales del complejo Midas Cichlidae, abordamos el concepto detrás del DNA Barcode como una técnica moderna de análisis genético e informamos sobre la investigación que realizamos en el Centro de Biología Molecular de la Universidad Centroamericana.

\section{Diversidad de peces en Nicaragua}

Muchas especies -algunas endémicas- se encuentran en peligro de desaparecer debido a factores como la pesca intensiva, la introducción de especies exóticas y la contaminación. El conocimiento de la diversidad de peces, tanto marinos como de agua dulce, que se encuentran en Nicaragua, es importante para poder protegerlos y conservarlos

En Nicaragua existen aproximadamente 640 especies de peces agrupados en 125 familias y 299 géneros. De éstos, 584 son peces marinos agrupados en 109 familias y 261 géneros, mientras que 56 son peces de agua dulce representados por 16 familias y 38 géneros. Sin embargo, según los registros del ICLARM (Internacional Center for Living Aquatic Resources Management) se cuenta con aproximadamente 772 especies de peces marinos y 52 de agua dulce.

Las familias de peces más abundantes y comúnmente distribuidas en Nicaragua son: Cichlidae (guapotes y mojarras), Characidae (sabalotes y machacas) y Poecilidae (perezcas) (Rueda, 2007).

Se reportan ocho especies endémicas, es decir, peces que son exclusivos para Nicaragua (Cuadro 1). Sin embargo, en los últimos ocho años se han reportado seis especies más pertenecientes al género Amphilophus. 
Cuadro 1. Especies de peces endémicas en Nicaragua

\begin{tabular}{|l|}
\hline \multicolumn{1}{|c|}{ Nombre científico } \\
\hline Dorosoma chavesii \\
\hline Hypsophrys nicaraguensis \\
\hline Cichlasoma zalliosum \\
\hline Astyanax nasatus \\
\hline Amphilophus labiatus \\
\hline Pomadasys grandis \\
\hline Rhamdia nicaraguensis \\
\hline Amphilophus rostratus \\
\hline
\end{tabular}

Fuente: Rueda, 2007.

\section{Complejo Midas Cichlidae}

El Complejo Midas Cichlidae se compone de especies del género Amphilophus, que difieren en morfología, hábitos alimenticios y sitios de reproducción. Hasta el momento hay reportadas nueve especies para el Complejo (Cuadro 2), pero posiblemente existan más (Stauffer, 2008).

Cuadro 2. Especies del Complejo Midas Cichlidae

\begin{tabular}{|c|c|}
\hline Amphilophus citrinellus (Günther, 1864) & \\
\hline Amphilophus labiatus (Günther, 1864) & \\
\hline Amphilophus zaliosus (Barlow, 1976) & endémico en laguna de Apoyo \\
\hline Amphilophus sagittae (Stauffer \& McKaye, 2002) & \multirow{3}{*}{ endémicos en laguna de Xiloá } \\
\hline Amphilophus amarillo (Stauffer \& McKaye, 2002) & \\
\hline Amphilophus xiloaensis (Stauffer \& McKaye, 2002) & \\
\hline $\begin{array}{l}\text { Amphilophus chancho (Stauffer, McCrary \& Black, } \\
\text { 2008) }\end{array}$ & \multirow{3}{*}{$\begin{array}{l}\text { endémicos en laguna de } \\
\text { Apoyo }\end{array}$} \\
\hline $\begin{array}{l}\text { Amphilophus flaveolus (Stauffer, McCrary \& Black, } \\
\text { 2008) }\end{array}$ & \\
\hline $\begin{array}{l}\text { Amphilophus astorquii, (Stauffer, McCrary \& Black, } \\
\text { 2008) }\end{array}$ & \\
\hline
\end{tabular}

Fuente: Black et al. (2008).

Las especies del Complejo se encuentran en los lagos Xolotlán y Cocibolca, y en las lagunas Xiloá, Apoyo, Apoyeque, Asososca (León), Asososca (Managua), Masaya, Tiscapa, y posiblemente en Moyoá y Monte Galán. 
Solamente se han realizado estudios completos -análisis ecológicos y genéticos- en peces de Xiloá y Apoyo, en donde se encontraron especies endémicas. Sin embargo se cree que puede haber especies endémicas en las otras lagunas.

Lo primordial en el estudio del Complejo Midas Cichlidae es hacer muestreos en las diferentes lagunas y lagos para conocer si existen nuevas especies. Para esto es necesario realizar análisis ecológicos, filogenéticos, morfométricos y de genética poblacional útiles para fundamentar adecuadamente la publicación de nuevas especies.

Los análisis ecológicos -comportamiento reproductivo y alimenticio-se hacen principalmente estableciendo sitios de estudio en los cuales se marcan transeptos que son recorridos por un buzo que graba a los peces o anota las actividades que éstos realizan -de acuerdo al interés de la investigación: comportamiento reproductivo o alimenticio- y luego analiza los datos utilizando métodos estadísticos que ayudan a determinar si es significativa o no la diferencia en la preferencia de lugares, época y profundidad de apareamiento, sitio donde colocan el nido y tipo de alimento (Mckaye et al. 2002).

Para los análisis morfométricos y merísticos se utilizan técnicas estadísticas como PCA (Principal Component Analysis) para identificar las variables que presentan la mayor variabilidad en los datos. Las especies son discriminadas en base a datos merísticos establecidos (Barluenga et al. 2006).

PCA es una técnica de análisis multivariante. La idea central del PCA es conseguir la simplificación de un conjunto de datos, generalmente cuantitativos, procedentes de un conjunto de variables interrelacionadas. Con ello se consigue 1. sintetizar la información procedente de un volumen importante de datos recogidos en una investigación en particular; y 2. utilizar el PCA como paso previo a otras técnicas (Almenara-Barrios et al., 2002).

\section{Análisis genéticos}

Se utilizan también diferentes tipos de análisis genéticos como los marcadores moleculares (Cuadro 3), que son puntos de referencia en un cromosoma que pueden o no corresponder a un gen. Diversas técnicas de biología molecular se usan para detectar la variabilidad en la secuencia de ADN como: la reacción en cadena de la polimerasa (PCR), las enzimas de restricción, la separación electroforética de los fragmentos de $\mathrm{ADN}$, las sondas marcadas y las hibridizaciones. 
Cuadro 3. Tipos de marcadores moleculares

\begin{tabular}{|c|c|c|}
\hline \multirow{6}{*}{$\begin{array}{l}\text { Marcadores } \\
\text { moleculares }\end{array}$} & \multirow[t]{2}{*}{$\begin{array}{l}\text { 1. Marcadores basados en } \\
\text { la hibridación del ADN }\end{array}$} & $\begin{array}{l}\text { RFLP - restriction fragment length } \\
\text { polymorphisms: (polimorfismos en la } \\
\text { longitud de fragmentos de restricción } \\
\text { de ADN). }\end{array}$ \\
\hline & & $\begin{array}{l}\text { Los minisatélites o VNTR - variable } \\
\text { number of tandem repeats: (número } \\
\text { variable de repeticiones en tándem). }\end{array}$ \\
\hline & \multirow{3}{*}{$\begin{array}{l}\text { 2. Marcadores basados en } \\
\text { la amplificación del ADN } \\
\text { mediante la reacción de } \\
\text { PCR - polymerase chain } \\
\text { reaction: (Reacción en } \\
\text { cadena de la polimerasa de } \\
\text { ADN). }\end{array}$} & $\begin{array}{l}\text { RAPDs - random amplified polymor- } \\
\text { phic DNAs: (fragmentos polimórficos } \\
\text { de ADN amplificadosaleatoria- } \\
\text { mente). }\end{array}$ \\
\hline & & $\begin{array}{l}\text { DAF - DNA amplification fingerprint- } \\
\text { ing y AP-PCR -arbitrary primer PCR: } \\
\text { (primers arbitrarios en PCR). }\end{array}$ \\
\hline & & $\begin{array}{l}\text { SSR -simple sequence repeats: (mic- } \\
\text { rosatélites) }\end{array}$ \\
\hline & 3. Marcadores mixtos: & $\begin{array}{l}\text { AFLPs -amplified fragment length } \\
\text { polymorphisms }\end{array}$ \\
\hline
\end{tabular}

Fuente: Carrera et al. (2004)

De los marcadores moleculares señalados en el Cuadro 3, los utilizados más frecuentemente en el estudio de los peces del Complejo son los AFLPs y los microsatélites.

\section{Especiación simpátrica}

El mecanismo de especiación es una de las interrogantes más importantes respecto al origen de las especies del Complejo Midas Cichlidae de las lagunas cratéricas de Nicaragua, por ser estas lagunas de origen reciente -aproximadamente. 23,000 años- y relativamente pequeñas, en las que las especies tienen que haber evolucionado rápidamente en un espacio limitado. Estas características llevan a pensar que en algunas lagunas de origen cratérico de Nicaragua se puede haber presentado la especiación simpátrica que consiste en la formación de especies en la ausencia de barreras geográficas (Barluenga et al. 2006). El mecanismo de especiación alopátrica, por otra parte, se refiere a la formación de especies en presencia de barreras geográficas, y es el mecanismo de especiación más común. Pero para demostrar que esto ha ocurrido es necesario encontrar dos o más poblaciones fenotípicamente discernibles, de origen monofilético y realizar análisis morfológicos, ecológicos, genéticos y filogenéticos, lo que es un tema de mucha controversia y sujeto a muchas interpretaciones (McKaye et al. 2002). 
En la edición del 9 de febrero de 2006 se publicó en la revista Nature el artículo "Especiación simpátrica en peces Cichlidos en una laguna cratérica de Nicaragua”. Presenta un estudio realizado por un grupo de investigadores de Alemania, quienes exponen un caso de especiación simpátrica en las especies del Complejo Midas Cichlidae en la laguna de Apoyo. El estudio utiliza análisis filogenéticos, de genética poblacional (técnicas moleculares), morfométricos y ecológicos, concluyendo que la especie Amphilophus zaliosus evolucionó a partir de Amphilophus citrinellus en un período de aproximadamente 10,000 años. También concluye que son especies aisladas reproductivamente y eco-morfológicamente distintas. Dicha publicación creó controversia entre grupos de científicos que piensan que aunque es muy probable que en dicha laguna, y en otras de origen cratérico, se haya presentado el mecanismo de especiación simpátrica, consideran que es necesario realizar más investigaciones para confirmarlo.

\section{DNA Barcode, Código de Barras genético}

En 2003, investigadores de la Universidad Guelph en Ontario, Cánada, propusieron el Código de barras genético, "DNA barcode", como una técnica para identificar especies. Un Barcode se puede considerar como una secuencia corta de ADN, de una localidad uniforme del genoma, usada para identificar especies.

La región de gen que está siendo utilizada como Barcode estándar para casi todos los grupos de animales es una región de 648 pares de base del gen mitocondrial citocromo c oxidasa sub unidad 1 (COI). Está probado que COI es altamente efectivo en la identificación de aves, peces, mariposas y muchos otros grupos de animales ${ }^{1}$.

Se escogió un gen mitocondrial debido a algunas de sus características:

1. Una célula posee más copias de $\mathrm{ADN}$ mitocondrial que de $\mathrm{ADN}$ nuclear, lo que permite recuperar el $\mathrm{ADN}$ con más éxito en muestras pequeñas o degradadas.

2. Hay mayor diferencia en la secuencia de ADN entre especies diferentes.

3. Hay poca diferencia en la secuencia de $\mathrm{ADN}$ de ejemplares de la misma especie. La variación intraespecífica en el ADN mitocondrial es baja en la mayoría de las especies animales. Por ejemplo, en 260 especies de pájaros norteamericanos estudiados, las diferencias entre especies estrechamente relacionadas tuvieron un promedio 18 veces mayor que las diferencias dentro de los especimenes de la misma especie.

4. Hay ausencia de intrones, que son $\mathrm{ADN}$ no codificante. En animales, los genes mitocondriales raramente contienen intrones. El ADN mitocondrial es generalmente transcrito directamente, en cambio, la amplificación de las regiones codificantes de genes nucleares es limitada a menudo por los intrones, que pueden ser muy largos (Ausubel, Stoeckle y Waggoner; 2005).

Uno de los principales objetivos de DNA Barcode es la estandarización, es decir, que esta técnica pueda ser utilizada para la identificación de especies por muchos investigadores, lo que permitirá acelerar la construcción de una biblioteca de secuencias de ADN que 
sea accesible y consistente. De esta manera, cualquier investigador -aún cuando no sea un especialista en taxonomía- en cualquier parte del mundo será capaz de identificar rápidamente de una forma confiable a qué especie pertenece un espécimen dado (Ausubel, Stoeckle y Waggoner; 2005).

DNA Barcode es una iniciativa internacional, por lo que cuenta con una red de repositorios en la Web con información general sobre la técnica, además de trabajos realizados, protocolos y contactos. Cada uno de ellos ha tratado de abarcar diferentes áreas en las que se está realizando investigación implementando la técnica. Aunque se reconocen algunas dificultades, los investigadores están tratando de mejorar errores para conseguir el objetivo principal que es la estandarización y confiabilidad de la técnica.

Los proyectos que emplean la técnica DNA Barcode, toman en consideración los siguientes aspectos:

1. El espécimen. Éste puede encontrarse en museos de historia natural, herbarios, zoológicos, acuarios, colecciones de tejidos congelados, bancos de semilla y otros reservorios de material biológico.

2. El análisis de laboratorio. Protocolos de DNA Barcode pueden ser utilizados para obtener secuencias DNA Barcode de los especímenes a estudiar. Esquemáticamente, el análisis de laboratorio se puede resumir en la Ilustración 1.

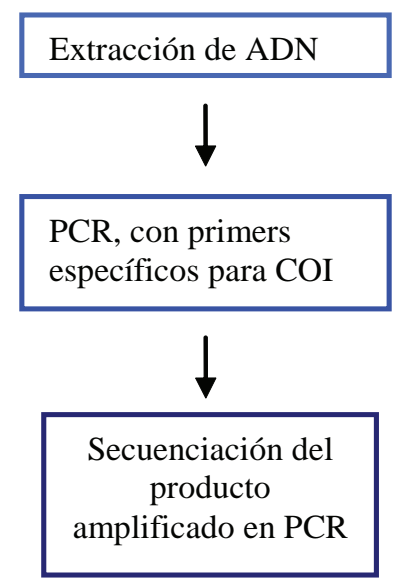

Ilustración 1. Análisis de laboratorio necesarios para realizar un DNA Barcode

3. La base de datos. Es uno de los componentes más importantes de la Iniciativa de Barcode pues representa una biblioteca pública de referencia de las especies ya identificadas donde se pueden encontrar las secuencias de los DNA Barcodes y comparar especímenes no identificados, con los que ya han sido identificados.

Hay dos bases de datos principales en las que podemos encontrar las secuencias de los Barcodes: a.) La Base de Datos Internacional de Secuencias de Nucleótidos. (The 
International Nucleotide Sequence Database Collaborative) es miembro de "GenBank" en los Estados Unidos de América, la Base de Datos de Secuencias de Nucleótidos (Nucleotide Sequence Database) del Laboratorio Europeo de Biología Molecular y El Banco de Datos de ADN en Japón. b.) La Base de Datos de Barcode de la vida (Barcode of life Database, BOLD²) fue creada y es mantenida por la Universidad de Guelph en Ontario, que ofrece a los investigadores una manera de colectar, manejar y analizar los datos de los DNA Barcodes.

4. El análisis de los datos. Los especímenes son identificados encontrando la pareja más cercana en el record de la base de Datos.

Cuadro 4. Ventajas de DNA Barcode

- Acceso global

- Demuestra el valor de las colecciones

- Permitirá Enciclopedia de la Vida

- Funciona para varias formas de vida: desde huevos y semillas, hasta organismos adultos

- Funciona con pequeños fragmentos. No es necesario utilizar grandes cantidades de tejido.

- Distingue entre especies muy parecidas

- Facilita el reconocimiento de nuevas especies

Fuente: Ausubel, Stoeckle y Waggoner (2005)

Cuadro 5. Principales limitantes al utilizar DNA Barcode

1. Desconocimiento de las partes no descritas de la biodiversidad. Esto es una dificultad porque se considera que DNA Barcode es una herramienta cuya utilidad principal es corroborar la identificación de especies antes descritas, cuya taxonomía es bien comprendida, y la parte "no descrita" pude ser un problema para DNA Barcode.

2. Riesgos inherentes debido a la herencia de los genes mitocondriales. Dado que el $\mathrm{ADN}$ mitocondrial es heredado por vía materna, el uso de loci mitocondrial puede conducir a sobreestimar la divergencia de la muestra y llegar a conclusiones imprecisas acerca del estatus de la especie. Además, la herencia mitocondrial entre individuos de la misma especie puede ser confundida como infección simbiótica y estas hibridaciones interespecíficas e infecciones endosimbióticas pueden generar transferencia de genes mitocondriales fuera de cada grupo evolutivo.

3. Confusión por copias nucleares del gen COI (NUMTs). Se refiere a copias nucleares de secuencias de ADN mitocondrial que han sido traslocadas dentro del genoma nuclear. Es posible equivocarse y secuenciar ADN nuclear en vez de ADN mitocondrial. 
Dificultad con especies que divergieron hace poco tiempo. En organismos cercanamente emparentados, que hace poco tiempo fueron reconocidos como especies diferentes, es posible que el DNA barcode de estas especies presente poca variabilidad y por ende no sean identificadas como especies diferentes4. (Frézal y Leblois, 2008).

DNA Barcode está bien establecido en animales. Sin embargo, en plantas no está aceptado todavía un Barcode universal. Primero se propuso a trnH-psba que es una región de ADN presente en un plastidio (Kress et al. 2005), pero recientemente se realizó un estudio con más de 1,600 muestras de plantas de Mesoamérica y África, en el que se compararon ocho diferentes Barcodes potenciales y se identificó una porción del gen matk, presente en el plastidio, que genera un adecuado rango de variación, una fácil amplificación y alineamiento y que parece ser un "Barcode" conveniente en plantas (Lahaye et al. 2008).

\section{Barcode en números}

Actualmente, de acuerdo a los datos presentes en BOLD System, hay 497,342 especímenes con Barcodes. De éstos, 64,173 se consideran especies. En el Cuadro 6 se muestran los Barcodes (números entre paréntesis) que hay por clase de los diferentes Reinos de la

Vida.

Cuadro 6. Número de Barcodes por clase de los Reinos de la Vida (adaptado de BOLD Systems)

\begin{tabular}{|l}
\hline Animales \\
Acanthocephala [190] \\
Annelida [6892] \\
Arthropoda [448841] \\
Brachiopoda [82] \\
Bryozoa [455] \\
Chaetognatha [35] \\
Chordata [140472] \\
Cnidaria [1648] \\
Cycliophora [273] \\
Echinodermata [3761] \\
Echiura [7] \\
Gnathostomulida [8] \\
Hemichordata [3] \\
Mollusca [22666] \\
Nematoda [2389] \\
Nemertea [358] \\
Onychophora [53] \\
Platyhelminthes [3121] \\
Pogonophora [256] \\
Porifera [649] \\
Priapulida [3] \\
Rotifera [1215] \\
Sipuncula [86] \\
Tardigrada [351] \\
Xenoturbellida [3]
\end{tabular}

Hongos

Basidiomycota [2556]

Eumycota [226]

Myxomycota [5]

Plantas

Magnoliophyta [7714]

Rhodophyta [3213]

Streptophyta [8]

\section{Protistas}

Bacillariophyta [606]

Ciliophora [279]

Dinozoa [113]

Heterokontophyta [1394]

Opalozoa [1]

Straminipila [1195] 
Hasta el momento el reino animal ha sido el más estudiado -cuenta con el mayor número de Barcodes reportados- quizá debido a que el segmento de ADN a utilizar fue establecido adecuadamente, lo que no ocurrió en plantas y en los otros reinos. Sin embargo, es necesario enfocarse en todos los seres vivos para que la técnica de DNABarcode sea realmente universal y pueda ser utilizada como una alternativa para la identificación de especímenes.

\section{Proyecto DNA Barcode en Especies del Complejo Midas Cichlidae, Centro de Biología Molecular}

En diciembre de 2007, el Centro de Biología Molecular inició este proyecto en colaboración con Jeffrey McCrary y Matthias Felix Geiger, de la Universidad Ludwig Maximilian de München (LMU). Gracias a dicha colaboración se colectaron 239 muestras. Las localidades donde se tomaron las muestras se expresan en el Cuadro 7.

Cuadro 7. Localidades y número de muestras colectadas

\begin{tabular}{|l|l|l|}
\hline \multirow{4}{*}{ Localidad } & \multicolumn{2}{|c|}{ Número de muestras } \\
\hline \multirow{4}{*}{ Lago de Nicaragua } & Puerto Díaz & 25 \\
\cline { 2 - 3 } & San Miguelito & 16 \\
\cline { 2 - 3 } & San Carlos & 17 \\
\cline { 2 - 3 } & Isletas de Granada & 21 \\
\hline Río San Juan & 19 \\
\hline Apoyo & 26 \\
\hline Tiscapa & 7 \\
\hline Xiloá & 52 \\
\hline Apoyeque & 18 \\
\hline Lago de Managua & 12 \\
\hline Monte Galán & 6 \\
\hline Asososca León & 16 \\
\hline Moyoá & 4 \\
\hline Total & 239 \\
\hline
\end{tabular}


Con el fin de obtener los Barcodes, la metodología comprende los siguientes pasos:

Extracción de ADN de las muestras colectadas (Aletas pectorales preservadas en etanol 100\% a $-20^{\circ} \mathrm{C}$.) utilizando el High Pure PCR Template Preparation Kit de ROCHE).

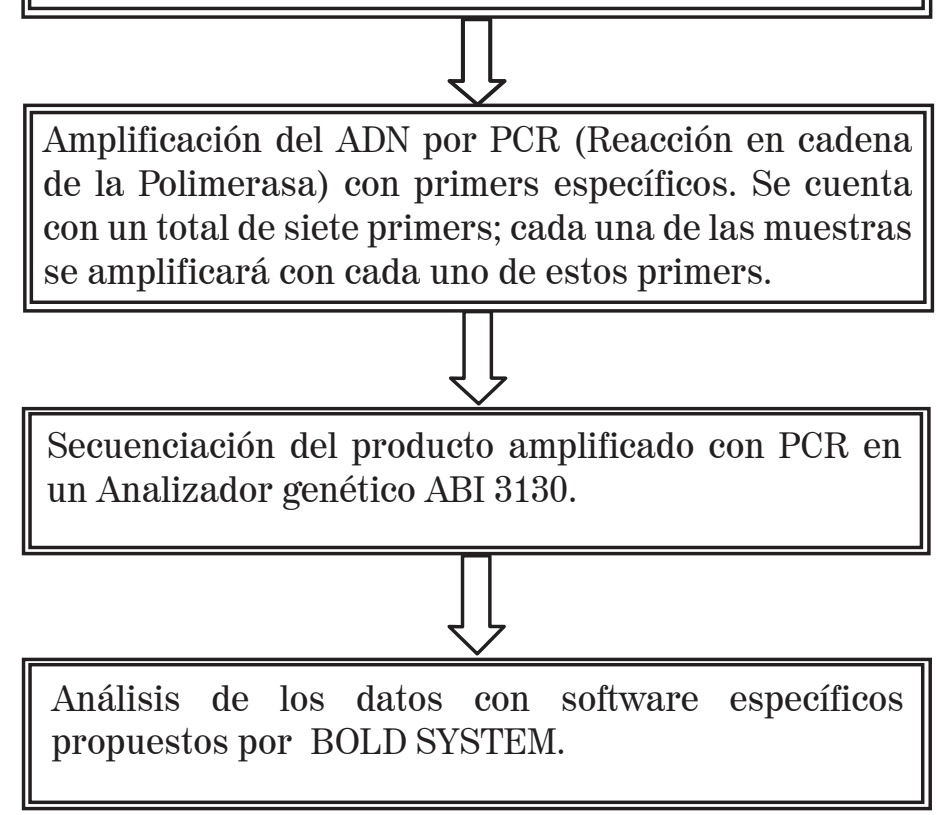

El estudio del Complejo Midas Cichlidae es de gran importancia debido a su valor evolutivo y, además, porque las especies del Complejo se encuentran amenazadas por la introducción de especies exóticas y sería lamentable que alguna despareciera sin antes haber sido reportada.

Con este proyecto se espera conocer el estado de la diversidad de especies del Complejo Midas Cichlidae en el país, lograr distinguir entre especies muy similares morfológicamente, que evolucionaron recientemente y que habitan en los distintos lagos y lagunas. Actualmente no hay investigadores nacionales trabajando en este tipo de estudios, por lo que con este trabajo se promueve la investigación en el país, utilizando técnicas modernas y abordando temas de actualidad y de importancia debido a que se trata de un grupo de especies únicas en Nicaragua. Además, esto podría interesar a turistas y podría generar empleos en el país, promoviendo la preservación de nuestros recursos naturales y en particular de estas especies y sus hábitats.

Existen cuestionamientos sobre la eficacia de la técnica al momento de elaborar análisis filogenéticos (Rubinoff, 2006), y la asignación de especies en un taxa dado. El Complejo Midas Cichlidae es bastante polémico, principalmente por su mecanismo evolutivo. No es posible anticipar resultados ni saber hasta qué punto la técnica podrá responder las interrogantes del número de especies existentes y el mecanismo de especiación. Entonces 
es necesario tener en cuenta los pros y los contras de la técnica y ser cuidadoso al momento de analizar los datos.

El descubrimiento de una nueva especie no se puede basar en una sola técnica, principalmente si son especies polémicas como el caso del Complejo, por lo que será necesario utilizar otras herramientas como los marcadores moleculares y estudios ecológicos. Sin embargo, DNA Barcode puede proporcionar una idea global de la situación de este grupo de peces y sobre todo -siendo la primera vez que se implementa en el país- nos dará la experiencia necesaria para poder utilizarla en el futuro en otras investigaciones sobre biodiversidad.

\section{Notas}

1CBOL. Disponible en: www.barcoding.si.edu/whatis.html .

2 Disponible en: www.barcodinglife.org .

\section{Referencias bibliográficas}

112 ALMENARA-BARRIOS， J.; GARCÍA-ORTEGA， C.; GONZÁLEZ-CABALLERO， J. L. \& ABELLÁN-HERVÁS, M. J. (2002) “Creación de índices de gestión hospitalaria mediante análisis de componentes principales”. Salud Pública México. 44(6):533-540.

AUSUBEL, J. H.; STOECKLE, M. \& WAGGONER, P. E. (2005) Barcoding Life, Illustrated. Disponible en página web de la Universidad Rockeffeller: http: phe.rockeffeller.edu. Consultada: 16 de octubre de 2008.

BARCODE OF LIFE DATABASE (BOLD) Disponible en: www.barcodinglife.org. Consultada: 7 de octubre de 2008.

BARLUENGA, M.; STÖLTING, K. N.; SALZBURGER, W. MUSCHICK, M. \& MEYER, A. (2006). "Sympatric Speciation in Nicaraguan Crater Lake Cichlid Fish". Nature 439:719-723.

BLACK, K. E.; MCCRARY, J. K. \& STAUFFER, J. R. (2008). "Three New Species of Cichlid Fishes (Teleostei: Cichlidae) from Lake Apoyo, Nicaragua". Proceedings of the Biological Society of Washington. 121(1):117-129.

CARRERA, A.; HELGUERA, M.; PICCA, A.\& SALOMÓN, N. (2004) "Marcadores moleculares”. En Echenique, V.; Rubinstein, C. \& Mroginski, L. (Ed). Biotecnología y Mejoramiento vegetal. Buenos Aires: Ediciones INTA.

CONSORTIUM FOR THE BARCODE OF LIFE (CBOL) Disponible en: www.barcoding.si.edu/ whatis.html Consultado: 16 de octubre de 2008.

FRÉZAL,L. \& LEBLOIS, R. (2008) "Four years of DNA barcoding: Current advances and prospects" Infect. Genet. Evol. doi: 10.1016/j.meegid.2008.05.005

KRESS, J. W.; WURDACK, K. J.; ZIMMER, E. A.; WEIGT, L. A. \& JANSEN, D. H. (2005) "Use of DNA barcodes to identify flowering plants". Proc Natl Acad Sci USA 102: 8369-8374

LAHAYE, R. ; VAN DER BANK, M.; BOGARIN, D.; WARNER, J.; PUPULIN, F.; GIGOT, G.; MAURIN, O.; DUTHOIT, S.; BARRACLOUGH, T. \& SAVOLAINEN, V. (2008). "DNA barcoding the floras of biodiversity hotspots". PNAS. 105 (8) 2923-2928.

MCKAYE, K. R.; STAUFFER, J. R.; VAN DEN BERGHE, E. P.; VIVAS, R.; LOPEZ PEREZ, L. J.; MCCRARY, J. K.; WAID, R.; KONINGS, A.; LEE, W. J. \& KOCHER, T. D. (2002). "Behavioral, morphological and genetic evidence of divergence of the Midas Cichlid species complex in two Nicaraguan crater lakes”. Cuadernos de Investigación 12:19-47. Managua: UCA 
Publicaciones.

MCKAYE, K. R. \& STAUFFER, J. R. (2002). "Descriptions of three new species of cichlid fishes (Teleostei: Cichlidae) from Lake Xiloá, Nicaragua”. Cuadernos de Investigación de la Universidad Centroamericana.12:1-18. Managua: UCA Publicaciones.

RUBINOFF, D.; CAMERON, S. \& KIPLING, W. (2006) "A genomic Perspective on the Shortcomings of Mitochondrial DNA for Barcoding Identification”. Journal of Heredity. 97(6): 581-594.

RUEDA, R. (2007) Recopilación de la información sobre la biodiversidad de Nicaragua. Managua: Universidad Nacional Autónoma de Nicaragua-León. Norwegian Ministry of Foreign Affairs. Inbio-Costa Rica. 